\title{
Divín FMPS
}

\section{Desobediência civil e terrorismo no pensamento de Michael Walzer}

Francisco Deusimar Andrade Albuquerque Graduado - Universidade Federal do Ceará

\begin{abstract}
Resumo: A obediência ao estado é uma questão não unívoca para a filosofia política. Especialmente se encarado numa perspectiva moral, pois nem sempre o direito positivo prescreve o necessário e suficiente para abranger os direitos dos cidadãos e dos grupos minoritários. Então, parece haver um "direito de desobedecer" - sobre isso parece que há consenso. Contudo, haveria um "dever (moral) de desobedecer"? Tal pergunta, no contexto do filósofo estudado, adquire um rumo próprio, pois a desobediência à sociedade maior só é justificada com a obediência de um grupo menor, dentro desse estado, que reivindica para si um direito que diverge parcial ou totalmente dos posicionamentos do estado. Quando, então, as obrigações morais de um grupo menor se tornam maior do que a obrigação para com o estado? Como se justificaria moralmente a desobediência ao estado e à Lei, qual tipo de "lógica moral" é assumida? A partir de então, é necessário aprofundar nos limites do modo de ação dessa desobediência. É exatamente nesse campo onde é questionado a moralidade sobre o terrorismo e seu modo de ação na sociedade hodierna. O argumento usado a favor do terrorismo parece ter uma justificativa moralmente clara: é uma situação-limite, por isso justificado usar recursos-limite. Assim, dois subtemas nos emergem: primeiramente, o terrorismo de fato é o "último recurso"? Então, mesmo sendo o último recuso, isso seria uma justificativa - ou seja, tornaria justo - tal ação? O objeto do trabalho delineado nessa perspectiva, é o dever de desobedecer ao estado, trabalhado a partir da moral, sem deter-se na casuística, e então os limites morais da desobediência civil.
\end{abstract}

Palavras-chave: Terrorismo. Desobediência civil. Moral.

Abstract: The obedience to the state is a dubious question to the political philosophy. Specially whether it's faced by a moral perspective, because the positive law hardly prescribes the necessary to cover all question about citizens' rights and minorities groups' rights. So, it's not impossible think about a "right to disobey", it seems a common sense in ethics. However, would there be a "duty to disobey", morally talking? This question, in the context of Michal Walzer's philosophy, acquires a own way, because disobeying a bigger society is just justified by obeying a smaller group, inside the state, that claims divergent positions of the big society - arguing that the positive law is not so fair for them, or that they are not covered by those laws. So the fundamental question is when the moral obligation of those minor groups became greater than the duty of obeying the greater society? How is justified this kind of disobedience? Talking about disobeying is necessary seeing the limits of those actions. Those limits will be argued based in human rights. It's in this matter, that it's questioned about terrorism and your way of action in the hodiernal society. The argument used in favor of terrorism argues about a morally clear question: it's a limit situation, so that it's justified to be used like a limit resource. So, appear two sub themes: the terrorism is, in fact, the "last resource"? Then, if it's the "last resource", it would be justified? The objective of these words is delineate the duty of disobey, in the moral view, and so the moral limits of civil disobedience. 
Keywords: Terrorism. Civil disobedience. Moral.

\section{Introdução}

O dever de obedecer ao estado certamente é um assunto muito relevante na história da filosofia, especialmente, na época moderna, na qual há a tentativa de justificar racionalmente, ou moralmente, o poder do estado, não mais recorrendo à religião ou à tradição, e sua forma de atuação na sociedade da época. Essa pergunta fundamental torna-se relevante quando se começa a entrever na história que essa é mais ou menos a época do surgimento dos Estados Nacionais, mais ou menos, bem estabelecidos - ou pelo menos os primeiros corpos políticos mais estruturados, que em seguida darão início às nações. Essa mudança estrutural da sociedade precisa de uma justificativa: porque a associação política estabelecida seria a melhor opção a ser vivida?

Contudo, o contexto social em que se vive atualmente é amplamente diverso; principalmente na sociedade ocidental em que parece haver já um consenso razoável sobre a justificativa da existência dos estados. Contudo, se a questão filosófica de antigamente era basicamente "se há o dever de obedecer ao estado instituído", atualmente a pergunta parecer ser o inverso: "há o direito de desobedecer ao estado instituído?", ou ainda mais seriamente: "há o dever de desobedecer?". A desobediência aqui citada tem um contexto específico relevante, não é qualquer tipo de desobediência civil - caso contrário, poderia simplesmente ser chamado de crime. A questão mais bem formulada seria: "há uma obrigação moral de desobedecer ao estado?".

Muitos filósofos políticos têm insistido em que a obrigação fundamental é obedecer às leis da sociedade organizada maior e de que se é membro. Para a maioria das pessoas, essa sociedade é o estado. [...] Mas a existência de uma obrigação fundamental de obediência significa apenas que a desobediência deve ser sempre justificada. (WALZER, 1977, p.20).

Vê-se que há, implícita à pergunta, uma afirmação forte, a distinção entre a moralidade e a lei positiva. Se ambas fossem consideradas idênticas, não haveria justificativa 
moral de desobedecer, já que qualquer desobediência ao estado - e assim à lei - seria imoral necessariamente.

$\mathrm{Na}$ atual sociedade pluralista em que se vive, a discordância sobre assunto políticos e morais é algo razoavelmente aceito, conquanto que a estrutura geral da sociedade não seja quebrada, em garantia do bem comum de todos. Assim, a desobediência normalmente não é simplesmente argumentada a favor "de um direito de desobedecer", mas parece ocorrer reconhecimento de uma obrigação nova, um dever de desobedecer numa circunstância específica. (cf. WALZER, 1977, p.9). Em suma, sua afirmação base é que "a obediência a esta lei, ou àquela é incompatível com nossas crenças morais", segue-se então o argumento necessário que "por isso devo desobedecer". (cf. WALZER, 1977, p.10).

Mas porque isso parece acontecer? Uma resposta plausível seria porque o vínculo com a sociedade maior parece ser mais fraco, em virtude de o status de ser partícipe desta não estar ligada a um ato intencional - por exemplo, ninguém escolhe nascer onde nasceu, viver numa comunidade política específica onde foi criado e educado, em um sistema moral como o já estabelecido; as pessoas simplesmente nascem onde nascem e crescem onde estão. $\mathrm{O}$ status de membro é muito mais forte em comunidades pequenas, em grupos menores. Assim, "a teoria do contrato social obviamente aplica-se melhor a grupos menores, como seitas, congregações, partidos, movimentos, uniões e clubes" (WALZER, 1977, p. 15). Pois o contrato supõe condições de conhecimento intelectual e moral das exigências do acordo - o que não é evidente numa sociedade maior, num estado; já que não esse tipo de participação não passa pela adesão da vontade (necessariamente) - e a possibilidade de fuga é evidentemente menor do que nas comunidades menores.

Parece, então, que a justificativa moral da desobediência civil está na obrigação de obedecer a um grupo menor dentro da sociedade maior - do qual faz parte a identidade da pessoa. Contudo, qual a natureza dessa reivindicação e qual sua relação moral com a sociedade maior no contexto democrático - e especificamente liberal? Outro ponto ainda que precisa ser analisado é se essa reinvindicação põe à prova o bem comum e a existência da sociedade maior. 


\section{Desobediência e Liberalismo}

Uma sociedade liberal baseia-se claramente na liberdade e na igualdade, contudo, essa liberdade e igualdade ganha na política um caráter bem específico: assumir as ideias e concepções de bem livremente, e essas concepções não tem uma hierarquia preclara de prioridade política. Sendo mais claro, as concepções de bem de um grupo minoritário não poderiam ser reconhecidos como melhores do que de outros, dentro de um estado liberal. Esse pluralismo é parte constitutiva de uma sociedade liberal.

Quando Aristóteles afirma que "se todas as comunidades visam algum bem, o estado ou comunidade política, que é a mais elevada de todas e que compreende todo o resto, visa e em grau maior que qualquer uma das outras - ao bem mais alto." O caráter positivo de tal afirmação é que numa sociedade maior, as concepções de bem encontram um campo mais vasto de realização. Porém a concepção de bem não é unívoca para todos os membros, ou comunidades, pelo menos na conjectura atual - que é o objeto que nos interessa. Há ainda que se levar em conta que o estado não inclui necessariamente todas as comunidades na sua execução e legislação. A vontade da maioria sempre levará consigo o estigma de que haverá alguma concepção de bem que não foi contemplada - pois não há consenso sobreposto pleno sobre o que seria o bem mais alto. (cf. WALZER, 1977, p.22-23).

Alguns teóricos liberais tentam afirmar a existência de um consenso sobreposto - e não o compromisso com os outros - como parte fundamental da existência de uma sociedade liberal, que "implica que não existe uma doutrina, total ou parcialmente abrangente, com a qual todos os cidadãos concordem ou possam concordar para decidir as questões fundamentais de justiça política" (RAWLS, 2003, p.45). Em contraponto aos liberais políticos, a posição comunitarista de Walzer parece indicar outro caminho, nas palavras do próprio Autor:

"Mas desejo tentar um argumento mais forte do que este. Quero sugerir que homens e mulheres têm uma obrigação fundamental de defender os grupos com os quais se comprometeram e de defender os ideais desses grupos, mesmo contra o estado, desde que sua desobediência não ameace a própria existência da sociedade maior ou as vidas de seus cidadãos." (WALZER, 1977, p.20).

Para argumentar tal, Michael recorre à teoria contratualista - que precisa ser intencional (e livre), para ter validade. Numa sociedade maior, participar dela não faz parte 
da intencionalidade do individuo, ainda que sua atuação ativa passe pelo crivo do arbítrio. Não se escolhe nascer numa determinada sociedade; a residência, assim, não faz parte completa do arbítrio, logo, um julgamento moral nesse sentido fica comprometido. Mesmo a possibilidade de fuga de uma sociedade maior é muito mais comprometida do que numa comunidade menor.

Ainda que Locke afirme que há, sim, a possibilidade de abandonar o estado, ou a mudança da residência, essa escolha parece ser muito significativa na atualidade, por envolverem outros critérios de análise - o abandono do lar, dos familiares, amigos e colegas, a tensão de ir para uma cultura desconhecida, etc. Porém, há como que uma "migração interna", que é a participação em grupos menores com reivindicações limitadas. Para estes grupos, a escolha de ser membro constitui ipso facto uma escolha moral, pela existência de alternativas (cf. WALZER, 1977, p.21-22).

\begin{abstract}
"Se, porém, os grupos em que as pessoas aprenderem a fazer objeções são suprimidos pelo estado, então desaparece aquela possibilidade. Pelo menos em um aspecto importante, o estado não será mais uma associação intencional. $\mathrm{O}$ estado só pode ser considerado como um grupo de cidadãos em harmonia quando são reconhecidos e permitidos grupos pequenos, com reivindicações limitadas" (WALZER, 1977, p.22).
\end{abstract}

Portanto, para remontar o argumento poder-se-ia dizer, primeiramente que a existência de grupos minoritários é fundamental numa sociedade liberal. Então, como esses grupos têm interesses diferentes - e às vezes conflitantes - é possível que haja reinvindicações limitadas dentro do corpo social. Se tais divergências não existissem seriamente, ou se fossem reprimidas pelo estado, não se poderia afirmar que há intencionalidade de participação dentro do corpo social - remontando a teoria do contrato social - assim, não seria uma associação plenamente humana, pois não seria livre. Concluise, então, que a liberdade de grupos minoritários, e então de cidadãos de uma sociedade maior dentro do grupo minoritário, faz parte constitutiva de uma sociedade liberal bem organizada, bem como seu direito de reivindicar de maneira moderada. 


\section{Os limites da ação desobediente}

Antes de começar esse tópico, é necessário fazer aqui uma distinção: tenta-se debater os limites da ação desobediente, não tanto do limite da desobediência civil - ou mais precisamente o objeto formal da desobediência (por exemplo, se seria justo uma desobediência e revolução completa contra o estado, ou uma discordância completa contra as leis, etc.).

Até aqui se vê que há o direito de desobedecer, e em alguns casos o dever de desobedecer - um dever, pode-se dizer assim, relativo, pois "a responsabilidade de um indivíduo é sempre para com alguma outra pessoa e sempre aprendida com alguma outra pessoa" (WALZER, 1977, p. 25). Assim, o dever para o com um grupo minoritário pode assumir - e de fato assume em diversos casos - uma obrigação "maior" do que o dever de obedecer ao estado, ou a uma sociedade maior. Pois parece que o status de membro é muito mais evidente num grupo menor do que na sociedade maior. Esse direito de reivindicar é constitutivo de uma sociedade liberal.

Contudo, parece haver limites na reivindicação dentro das quais são permissíveis, e até favoráveis à sociedade democrática, pois seria uma maneira prática de haver uma comunicação de ideias e concepções de bem entre o grupo minoritário e a sociedade como um todo - e assim os diversos grupos minoritários. Desse modo, quais são os limites possíveis? Normalmente se debate que os limites vão até os cidadãos não envolvidos - não se deve oprimir diretamente estes - e pelas autoridades do estado - a não-resistência a estes quando eles executam a lei. Contudo essa insistência na não violência parece ser bem imatura do ponto de vista filosófico, pois ignora o poder que a desobediência efetivamente tem sobre os "não envolvidos" - e normalmente uma reivindicação tem o desejo de conseguir mais adeptos dentre aqueles que não estão envolvidos; depois porque ignora a violência real exercida pelos órgãos do estado, especialmente a polícia. (cf. WALZER, 1977, p.26-27).

Uma reivindicação pode até mesmo tomar um caráter violento dentro de limites razoáveis, sem que seja completamente imoral. De fato, uma moralidade ideal parece requerer das circunstâncias ideais. Na realidade, parece haver meios-termos de defesa e oposição que precisam ser levantados, e levados em conta.

Walzer, contudo, não argumenta a favor da violência física como constitutiva do ato de reivindicar (ainda que seja possível pensar numa reivindicação com violência moderada), 
mas apela a outras formas de pressão como preferíveis, por exemplo o sigilo, a disciplina a força e a resistência (com ou sem violência) (cf. WALZER, 1977, p.32). Pois estas parecem visar mais às instituições e órgãos da sociedade maior do que as pessoas nelas envolvidas moralmente o objeto de ação muda completamente; mas também psicologicamente parece haver essa distinção: "não ataco um alvo por raiva ou revolta, mas por um objetivo moral compartilhado", pelo menos implicitamente é isso que se espera de uma reinvindicação séria: uma reivindicação contra instituições e estruturas. "Uma reivindicação não-séria não pode jamais ser um dever" (WALZER, 1977, p.24).

Já que é possível pensar a desobediência violenta como moral, então quais os limites dessa violência? O terrorismo como pressão real e simbólica pode ser encontrada como um possível meio moral de ação dos grupos minoritários?

\section{Terrorismo e o problema da mira}

A partir do momento em que é admitido o "direito à rebeldia", ou o "direito à desobediência", é necessário debater sobre os meios empregados para tal. Dentro da denominação do trabalho, não serão tematizadas as questões do terrorismo internacional e dos problemas de ingerência, mas quase exclusivamente o terrorismo como recurso de luta civil.

O terrorismo, por definição, é a aplicação de terror para se alcançar um fim político delimitado e expostamente conhecido. "A aleatoriedade é característica crucial da atividade terrorista" (WALZER, 2003, 335). Exatamente por essa característica é necessária, para efetivação dos objetivos tentados que os revolucionários e ativistas divulgam seus objetivos e demonstram sua força - caso contrário seria simplesmente o emprego niilista do poder e do medo. Assim, os objetivos precisam ser divulgados e expostos para todos. Afinal, a única maneira de um "problema das minorias" tornar-se conhecidos é pela divulgação e amplitude de seu projeto político, "as guerras revolucionárias e subversivas se ganham nos corações e nas mentes das pessoas" (VAZ, 2006, p.94).

Essa temática é extremamente controversa, pois há os que o defendem como prática legítima de intervenção política. Não que seus defensores sejam necessariamente a favor do emprego da guerra, do terror, do medo e da destruição; mas que defendem essa maneira de se defender, exatamente por serem eles constantemente abusados e usurpados em suas 
determinações próprias. Pois o emprego do terrorismo remete sempre ao último recurso de grupos minoritários, como uma reação imediata e quase reflexiva por um abuso sofrido, ou acumulado durante os anos. Em suma, tenta-se alocar o terrorismo como um método de defesa.

"Uma batalha heroica entre o indivíduo [ou um grupo pequeno de indivíduos] e o estado seria terrivelmente desigual" (WALZER, 1977, p.24). Exatamente por essa falta de desproporcionalidade (política), em um dos lados, é possível justificar a falta de proporcionalidade (moral) no outro lado. Mas será esse um argumento verdadeiramente válido e sólido? Insistir sobre a discussão do último recurso é realmente possível? Como se pode saber que se chegou ao último recurso? Como se pode saber que todos os demais recursos foram usados?

[...] o 'último recurso' só é último em termos de noção; o recurso ao terror é ideologicamente o último, mas não é o último numa série real de ações, é apenas o último em termos de desculpa. Na realidade, a maioria das pessoas que recomendam uma política de terrorismo, recomendamna como uma primeira instância. (WALZER apud VAZ, 2006, p.98).

Parece que a opinião a favor do terrorismo tende a ver somente uma das fases do emprego do terror, enquanto uma legitimação moral necessitaria colocar em balanço todos os fatores envolvidos. Uma resposta aceitável, ou moral, deveria se questionar também sobre a vida, a liberdade e os direitos dos não envolvidos, dos inocentes, dos não políticos, etc. $\mathrm{Ou}$ até mesmo, questionar-se até que ponto os políticos são, ou não, inocentes, até onde pode estabelecer-se um limite para o terror empregado (etc.).

$\mathrm{O}$ argumento a favor do emprego do terrorismo, como atividade legítima dos grupos minoritários, parece estar sendo efetivado por um cálculo utilitarista muito tendencioso, com a desculpa de que o malefício (ou a morte, para sermos mais claros) de uns poderia ser justificado pelos benefícios da sociedade "como um todo" - pelo menos psicologicamente parece essa ser a justificativa dos que usam de tal recurso. Em suma, a vida dos homens - de todos, não só dos envolvidos, pois num terrorismo todos correm um risco real de serem vítimas - é vista como mera matéria, com cujas vidas podem-se montar uma estratégia de dissuasão. (cf. WALZER, 2003, p.364). Tal cálculo desumaniza os homens, e os torna objetos de estratégia política. 
Contudo, o argumento não pode ser visto simplesmente a partir do ponto de vista dos grupos minoritários. Existem outros fatores (morais) que precisam ser analisados. O primeiro deles são as vítimas. Este é exatamente o problema central do terrorismo contemporâneo, a falta de uma limitação para a ação: todos são alvos, todos são vítimas em potencial, não há uma segurança prevista para nenhuma espécie de pessoa, não descriminação entre o rico ou o pobre que pegam metrô na hora errada, entre o branco, preto ou asiático que se encontram numa praça pública na hora da ameaça.

Essas pessoas (as vítimas) definitivamente não tem nenhuma ligação com os enlaces políticos que o terrorismo parece elencar. Essas pessoas são instantaneamente destituídas de suas características humanas, de seus direitos fundamentais - de seus direitos humanos -, e o pior, sem nenhuma justificativa (moral) para isso. Em um minuto são cidadãos de fato e de direito. Poucos segundos depois, sem nenhuma mudança nas situações efetivas, elas são simplesmente descartadas, como objeto de persuasão política? Como se pode justificar isso moralmente? O problema mais sério, aqui no caso, não é simplesmente a violência empregada, mas a falta de justificativa para tal violência. Apesar de o caso parecer ser semelhante ao de um soldado em guerra, são situações completamente distintas - pelo simples fatos de nenhum cidadão ter se empenhado numa luta, ou combate direto a favor de um sistema opressor. Um ou outro cidadão pode ser partidários, militantes, etc., mas o alvo dos terroristas é indiscriminado: todos são vítimas em potencial.

Contudo é preciso ir além na argumentação: mesmo os cidadãos e políticos envolvidos numa causa denominada de opressora podem ser alvos legítimos de retaliações severas? Eliminar os representantes ou partidários contrários será o fim da opressão?

\footnotetext{
"Soldados e autoridades são, porém, diferentes sob outro aspecto. A natureza ameaçadora das atividades do soldado é um ponto pacífico. A natureza injusta ou opressora das atividades da autoridade é uma questão de avaliação política. Por esse motivo, o código político nunca atingiu o mesmo patamar que as convenções de guerra. Os assassinos de figuras importantes também não podem reivindicar nenhum direito, mesmo com base na mais rigorosa adesão a seus princípios." (WALZER, 2003, p.341-342).
}

Nota-se isso principalmente porque uma autoridade tem muito mais um poder simbólico dentro de um conflito do que um poder real. Mais claramente, a morte de uma autoridade dará continuidade a sua substituição - utilitariamente falando - e a opressão 
continuará. Por isso, nem a violência aos civis, nem às autoridades correspondentes parecem oferecer uma resposta moral adequada às reinvindicações dos grupos minoritários, pensando a partir dos direitos humanos.

\section{Conclusão}

Vemos nos desenvolver da temática abordada as características próprias de uma desobediência civil bem ordenada nos moldes dos direitos humanos. Por mais contraditória que pareça, a desobediência civil parece não diminuir a amplitude de uma democracia baseada nos princípios liberais, mas pelo contrário alargar seu campo de ação - já que a participação efetiva na sociedade parece estar ligada ao status de membro e não só de cidadão.

A participação, então, de uma comunidade e o vínculo moral que une os companheiros dessas comunidades parece assumir uma ligação mais forte que a associação numa sociedade maior. Ser membro traz uma responsabilidade muito maior do que ser um cidadão. Pois o estado e a sociedade como um todo não tem um rosto, sua história compartilhada tem muito menos enlaces do que a comunidade da qual um membro participa, etc. O sentido de pertença é muito mais claro nas comunidades menores; a possibilidade de aderir e até mesmo contribuir com a mudança e construção de uma comunidade menor é muito mais evidente e a possibilidade de fuga é bem mais fácil.

Para a sociedade democrática é fundamental a existência dessas comunidades menores com diversas concepções de bem. A supressão delas seria uma contradição moral contra pluralismo e assim contra a democracia como um todo (afinal a supressão de grupos minoritários não é "a especialidade" do totalitarismo?). O consequente desentendimento entre os grupos minoritários e entre esses grupos e o estado faz parte do processo de democratização da sociedade. Entender os conflitos e reivindicações, as pressões políticas, as passeatas, a propagandas, etc. como maneiras práticas desse diálogo ocorrer é fundamental para a politização dos indivíduos envolvidos numa sociedade democrática.

Ainda que a tendência habitual seja a de supressão de qualquer tipo de pressão ou violência que pareça radical, é necessário que esses meios sejam elevados ao nível do diálogo social, muito mais do que como revolta pessoal ou opressão de um grupo específico. $\mathrm{O}$ protesto de grupos minoritários vem se mostrando como uma maneira eficaz de se fazer ouvir 
pela sociedade em suas necessidades fundamentais, não só como indivíduos, mas como membro de tais comunidades.

Contudo, o diálogo e a amplitude do debate social não podem ser atingidos dentro de determinados níveis de violência e agressão - física ou simbólica. Por isso, a moralidade deve ser pensada tendo como base os direitos humanos, sem o qual não se há um desenvolvimento integral da democracia e dos povos. Quando passado alguns limites dentro do debate social, ao invés de haver diálogo e compreensão entre os grupos minoritários ou entre esses e o estado, começa a despontar a violência e a opressão. E essas parecem não levar a soluções, mas conduzem a mais conflitos.

\section{Referência Bibliográfica}

RAWLS, John. Justiça como equidade: uma reformulação. Tradução: Claudia Berliner. São Paulo: Martins Fontes, 2003.

VAZ, Nuno Mira. Guerra Justa em tempo de Terrorismo: reflexão em louvor de Michael Walzer. Nação e Defesa. $3^{\circ}$ serie. $n^{\circ}$ 113. p. 91-106. Primavera. 2006. Disponível em: $<$ http://comum.rcaap.pt/bitstream/123456789/1111/1/NeD113_NunoMiraVaz.pdf $>$. Acesso em: 18 de fevereiro de 2014.

WALZER, Michael. Guerras Justas e Injustas: uma argumentação moral com exemplos históricos. São Paulo: Martins Fontes, 2003.

- Das obrigações políticas: Ensaios sobre desobediência, guerra e cidadania. Tradução: Helena Maria Camacho Martins Pereira. Editora Zahar: Rio de Janeiro, 1977. 